\title{
Flipped classroom instructional strategy in teaching mathematics to grade five learners: Basis for video-assisted instructional materials
}

Esquillo, Jonnel P.

Emilio Aguinaldo College, Philippines (mommyjonnela15@gmail.com)

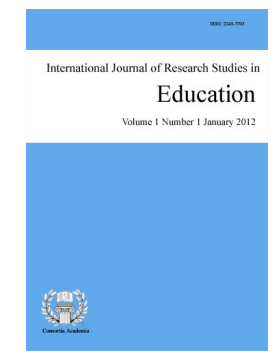

ISSN: $2243-7703$ Online ISSN: 2243-7711

Received: 30 March 2021

Revised: 14 May 2021

Accepted: 30 May 2021

OPEN ACCESS

\section{Abstract}

This study is an experimental research that aimed to determine the effectiveness of the Flipped Classroom Instructional Strategies in teaching Mathematics 5. The control group, comprising of 34 pupils, and the experimental group composing of 35 pupils was tasked to provide their age, and sex. The conventional teaching method taught to the control group, while the Flipped Classroom Approach taught for a period of two (2) weeks to the experimental group. Surveyed students are in appropriate age for their current grade level. The study is dominated by male respondents. Respondents from control and experimental group have low to average performance during the pre- test. Performances of control group and experimental group have increased. Though, experimental group has higher post-test score rating than control group. Pre-test scores of both groups do not have significant difference. Also, it depicts that the ability of respondents on both control and experimental is almost at the same level. An intervention should be used to improve their performance. Posttest scores of both groups have significant difference. Although there is an increase on the performance of the control group, experimental group has performed even better. The use of flipped classroom instructional strategies in teaching Mathematics is deemed effective.

Keywords: flipped classroom instructional strategies; conventional teaching method; flipped classroom approach; innovation; improve 


\section{Flipped classroom instructional strategy in teaching mathematics to grade five learners: Basis for video-assisted instructional materials}

\section{Introduction}

Education in the twenty-first century includes core competencies such as teamwork, technical learning, critical thinking, and problem-solving, which educators believe must be taught to students for them to thrive in today's world. The flipped classroom curriculum approach is a modern set of educational principles that encourage hybrid learning with the help of teachers as guides and technology to re-imagine schooling in the twenty-first century and prepare students for adulthood.

The term "flipped classroom" refers to a pedagogical phenomenon in which students switch from community to individual learning spaces for direct instruction. The term "flipping the classroom" refers to students getting their first exposure to new content in an instructional video in the classroom. Learners will now prepare for problem-solving, conversations, and knowledge sharing since they have first learned the lesson. Previously, the teacher was at the core of the teaching and learning process, and they were the primary source of classroom information. Still, in this type of classroom, an instructional video is used to impart knowledge.

This method is becoming popular in many schools. However, in Pipindan Elementary Schools (PES), this approach has not been tried to teach Mathematics 5. PES is located along Everlasting Street in Pipindan, Binangonan, Rizal. It started its operation as an institution in 1937, wherein Ms. Dumandan was the first teacher with seven pupils. She used the "silong" of the house of Ka Dando as her classroom. Barrio folks during that time had seen the importance of education. Through the support of the barrio leaders, Miss Dumandan acquired projects to construct the school building.

The Flipped Learning Network (FLN) developed four foundations for FLIP in 2014, which are also the foundations of this research. First, the FLIP model emphasizes a flexible environment that allows for different learning modes; teachers often realign their learning ability physically to suit a course or class, assisting neither society nor independent research study. Second, to create an open atmosphere in which students can study whenever and wherever they want. In reality, teachers who change classrooms are consistent in their assessments of student learning and expectations of student plans.

Bruner (1966) and Piaget (1970), two generally accepted constructivist theorists, propose that students construct their learning by solving problems with limited initial assistance from the teacher. Constructivism proposes that students build their knowledge base by reading like that of inquiry, in which students learn new information through experience rather than lecture (Lotter, Marshall, Sirbu, \& Smart, 2016; Rusche \& Jason, 2016).

As a result, high school mathematics classrooms lack a clear outcome or set of consequences. These are student-centered teaching methods, as opposed to the direct lecture that comes with teacher-centered education. Suppose an instructor uses a traditional lecture where the teacher is the authoritative figure or more modern, student-centered teaching methods. In that case, they should be willing to develop lifelong learners with a positive attitude and critical thinking skills such as evaluating problems or even problem solving using previously learned content.

Elimination in face-to-face instruction encourages pupils to study and learn through other mechanisms such as collaborative work or teacher preparation with peers (The teaching approach has made student instruction open). Students will watch the videos and complete a series of activities to demonstrate their understanding of the content. Studies have illustrated both task completion and time management (Bergmann \& Sams, 2017). Several different learning styles were often explored in the program process (Marlowe, 2017). Parents and 
administrators could also present the content for student education. Given all the recorded advantages of using the flipped classroom layout, certain teachers have found limitations in using this kind of teaching. According to the Electronic Education Report [ EER], teachers who used the flipped-out classroom saw good results in their classrooms (2017). Students will contribute much more to their education by solving problems with other students and the teacher. Students began to take charge of their education, and professors began to converse with teachers rather than students (EER, 2017). Reduced face-to-face learning encourages students to explore and learn by other means, such as classroom collaboration (Moore \& Gilmartin, 2015). Students have the potential to exit the classroom, seeking ambiguous answers, and worry about unclear details once they get home (Bergmann \& Sams, 2017). Many reasons for using the flipped classroom layout were discussed.

Compared to conventional teaching, the role of the educator is much more important and often required in Flipping a Class. They will track their students in class, providing them with valuable knowledge and reviewing their work. Professional educators must reflect on their abilities, work with others to improve their curriculum, accept criticism, and, most importantly, endure organized turmoil within the classroom. In a flipped learning classroom, skilled instructors have little visible liability, but they are also the critical capsule that allows Flipping the Learning to occur. According to Moffett (2015), the inverted classroom is a modern paradigm in which conventional teaching components and student assignments are flipped. The author's suggestions and experience with the technique in medical education are based on existing literature. The benefits of a new program have many advantages between the teacher and the learners.

Some of the factors that contributed to this were flexibility, individual focus, and changes in teacher structure (Nolan \& Washington, 2018). Students have been open about their curriculum thanks to the teaching method (Bergmann \& Sams, 2017). Parents and administrators should also present content to help students navigate the road to schooling. Despite using the flipped classroom layout, some teachers have found some disadvantages to this teaching method. Problem-based learning (PBL) is a method of learning in which students are presented with problems and must determine what additional knowledge is necessary, apply that knowledge, and then find the answers in sequential order (Cerezo, 2015).

The didactic, straightforward teaching lecture was moved away from the classroom and into a more student-friendly digital development environment with such a tilted lecture. Through a flipped classroom, the core principle of pedagogy did not change; rather, passive listening and teaching were transformed into active student participation (Nolan \& Washington, 2018). The teacher did not even need to use recordings because of content easily found on Internet sites like Khan Academy, YouTube, or Ted (Tucker, 2017).

Many elementary schools worldwide are just tangentially interested in mathematics, and academic performance is mediocre at best. By incorporating a revised teaching model and comparing student involvement in the reverse class in a conventional framework, this research study aimed to increase student participation and achievement in elementary mathematics. The flipped educational paradigm is a new teaching technique that aims to increase student engagement and achievement by taking lessons outside of the classroom through electronics and shifting study and practice inside the classroom to topics. A pre-and post-survey questionnaire, a unit assessment produced by teachers, informal interviews, and a focus group session were used to investigate and evaluate changes in the student participants' attitudes and behaviors. In addition, everyday thoughts, interactions, emotions, and opinions were documented in a newspaper interference by the writer. Compared to traditional classes, the student participants registered positive quantitative and qualitative results, indicating that they responded favorably to the slippery model of training and enjoyed increased participation and interaction. Students also noted an increase in the standard of education and the resources used in the flipped teaching style. Clark et al., 2015).

This analysis aims to evaluate the efficacy of the Flipped Classroom Instructional Strategy with a group of Grade 5 students. In addition, the researcher hopes to verify its efficacy in Pipindan Elementary School and propose delivery methods for effectively implementing the approach in the Mathematics classroom. 
Every day, children use technology in various ways, and teachers have been using it to their advantage in many classrooms for many years. The flipped classroom, also known as the twisted classroom, was popular in the late 1990s and early 2017s, and it brought what was usually done in the classroom into the workplace (Lage et al., 2017). Students may have had access to a digital device for Internet use. Several schools have experimented with BYOD (bring your device) student configuration (Schachter, 2017). In a BYOD school, students who have a laptop, a tablet, a mobile device, or another system can use these devices to enhance their learning. The flipped classroom incorporates new concepts into schools and societies by allowing students to use more technology. To enhance learning outcomes, educators should cultivate their professional expertise and incorporate it among students. This educational approach, known as the flipped classroom, has been successfully implemented in college courses at Yale, MIT, and Stanford (Bull, Ferster \& Kjellstrom, 2017). According to the theory, students engage with new content outside of class first and then incorporate it into their classroom learning. Students will watch the videos and complete a series of activities to demonstrate their understanding of the content. Studies have illustrated both task completion and time management (Bergmann \& Sams, 2017). The concept of spinning and turning the classroom isn't new (Baker, 2017; Strayer, 2007). To distribute the material to flipping classes, distance learning used educational video presentations. In the 1920s, a trend arose of using cutting-edge technologies, such as television and radio, to provide guidance (Byrne, 2015).

This study is designed to benefit the following: Department of Education (DepEd), findings of this piece of work, will give a framework of directory, guide, and bases in the aspects of flipping the class implementation. This can be used to improve the application of flipped classroom models in the division. For Curriculum Planner, this study will encourage developing curriculums according to the needs, abilities, interests, and learning preferences. For School Administrators, this study will challenge school administrators to create new ideas and improve instructions to strengthen the theoretical and empirical fibers of learning in Mathematics. It will also a way towards the realization of Flipped Classroom as an effective means in the improvement of academic achievement in all learning areas. For Teachers, this research will inspire teachers to adapt their lessons and approaches for long-term learners who can benefit from their curriculum in circumstances in the real world. This study hopes to inspire teachers of this generation to utilize a variety of techniques in teaching and instructional methods that will address the needs of each learner inside the classroom. For the Learners, equal education is the privilege of every learner, even though students have a wide variety of skill levels and bits of intelligence. This research should respond to everyone's long search for knowledge. Above all, Mathematics as a discipline in our country will also benefit from improving and utilizing the flipped classroom model. This said strategy is the most suitable teaching method in the country's current curriculum- the 2019 Secondary Education Curriculum (SEC), which follows the $\mathrm{K}$ to 12 curricula model.

\section{Methodology}

The process used in the study is quasi-experimental. Experimental research denotes a study preceded by a scientific approach, in which a set of variables are kept unchanged. In contrast, the other set of variables are being measured as the respondent of the experiment. In this study, two groups will be subjected to the experiment, the experimental and control group. However, only the group in experimental was exposed for the implementation of Flipped Classroom Approach. The group in control was instructed using the conventional approach. The study subjects are composed of two sections of the Grade 5 pupils of Pipindan Elementary School (PES) who comprised the control and experimental groups, respectively. These pupils were selected regardless of age, sex, and number. These pupils were the learners in the said school for the Academic Year 2019- 2020 as Grade 5 pupils.

The researcher-made test was employed for this study. The respondents were given a pre and post-test to determine the flipped classroom effectiveness in teaching Mathematics 5. The lessons included are the topics for Second Grading Period. The group in control was imparted in the traditional learning method. In contrast, the 
group in experimental was subjected to the flipped classroom learning style by the implementation of developed and adapted video instructed materials in Mathematics. To determine the validity and reliability of the instrument, the researcher submitted the program to his adviser and five (5) other experts who performed face validation. Then, the same was subjected for administration to the experimental group to determine its effectiveness.

The researcher submitted the Flipped Classroom pretest and post-test to his adviser and five (5) experts in the field for face validation. Next, the researcher showed some of the daily lesson log (DLL) using the flipped Classroom Approach for review. Next, the researcher seeks approval from his principal and the Schools Division Superintendent (SDO) to conduct experimental research. Finally, the researcher made a video lecture about understanding ratios and adapted the other videos on YouTube by simply writing permission to use the video lectures in his study. After the researcher received approval from the principal and the SDO, he began the study utilizing meetings with the parents of the respondents and the teachers, followed by flipped classrooms' orientation to the respondents of the experimental group.

The administration of the program ran for at least two weeks. Before the administration, a pretest was conducted. The respondents for the experimental group watched the videos outside of the class, usually in their homes. They were using technology such as cellphones and personal computers. The links of the videos in ratio and proportion that they need to watch were given by the researcher via writing on the board and sending to their group chats. In-School, the experimental group needs to do their assignment/homework individually. The result of the said task where the learners got low marks will focus on the activities and seat works that the respondents need to accomplish. The control group was imparted the traditional teaching approach where the lecture should be done in school, and at home, the learners need to do their assignment or homework. After implementing the program, to predict the program's effectiveness, a post-test was given.

The following statistical tools were used in this study: Frequency and Percentage Distribution. This was used to determine the age and gender profiles of the subject pupils. $t$-Sample was used to assess the important difference between the test scores of the study group's pupil-subjects. Analysis of Variance (ANOVA) this tool was used to determine the significance of a group's post-test scores in an experimental setting when their profiles are used as test factors. The analysis followed all ethical guidelines, including obtaining approval from the Ethics Research Committee and sending out introduction letters to all main informants. In addition, key informants and other research participants were asked for their consent after being told of the study's intent, dissemination of results, confidentiality, and willingness to participate.

\section{Findings and discussion}

This study determined the effectiveness of Flipped Classroom Instructional Strategies in teaching Mathematics to Grade Five Learners in Pipindan Elementary School (PES). The results of the study may be used as a reference for video-assisted instructional materials. Moreover, the gathered data are presented here with the analysis and interpretation based on the stated objectives of the study. These include the profile of the learner respondents in terms of sex and the pretest and post-test results. Differences in their assessment when their profile is taken as test factors were also as a result of this discussed, and arriving on the efficacy of flipped classroom instructional strategies.

\section{Table 1}

Percentage distribution and Frequency of respondents in terms of age

\begin{tabular}{|c|c|c|c|c|c|c|c|}
\hline \multirow{2}{*}{ Category } & & \multicolumn{2}{|c|}{ Control } & \multicolumn{2}{|c|}{ Experimental } & \multicolumn{2}{|c|}{ Total } \\
\hline & & $\mathrm{F}$ & $\%$ & $\mathrm{~F}$ & $\%$ & $\mathrm{~F}$ & $\%$ \\
\hline Ten years and below & & 27 & 79.4 & 35 & 100.0 & 62 & 89.9 \\
\hline 11 years old & & 7 & 20.6 & 0 & 0 & 7 & 10.1 \\
\hline 12 years above & & 0 & 0 & 0 & 0 & 0 & 0 \\
\hline & Total & 34 & 100.0 & 35 & 100.0 & 69 & 100.0 \\
\hline
\end{tabular}


Table 1 depicts the percentage distribution and Frequency of learner-respondents in place of age. The majority ( $\mathrm{f}=27,79.4$ percent; $\mathrm{f}=62,89.9$ percent) of the respondents from the control group and experimental group are ten years old, and the remaining ( $f=7,20.6$ percent; $f=7,10.1$ percent) are 11 years old. This suggests that surveyed students are at an appropriate age for their current grade level.

Table 2

Percentage distribution and Frequency of respondents in terms of sex

\begin{tabular}{lccccccc}
\hline \multirow{2}{*}{ Category } & \multicolumn{2}{c}{ Control } & \multicolumn{2}{c}{ Experimental } & \multicolumn{2}{c}{ Total } \\
\cline { 3 - 8 } & & $\mathrm{F}$ & $\%$ & $\mathrm{~F}$ & $\%$ & $\mathrm{~F}$ & $\%$ \\
\hline Male & 23 & 67.6 & 16 & 45.7 & 39 & 56.5 \\
Female & 11 & 32.4 & 19 & 54.3 & 30 & 43.5 \\
& \multirow{2}{*}{ Total } & 34 & 100.0 & 35 & 100.0 & 69 & 100.0 \\
\hline
\end{tabular}

Table 2 views the percentage distribution and Frequency of learner-respondents instead of sex. Most $(\mathrm{f}=23$, 67.6 percent; $f=39,56.5$ percent) of the respondents from the control group and experimental are male; and some $(\mathrm{f}=11,32.4$ percent; $30 ; 43.5)$ are female. It indicates that male respondents dominate the study.

\section{Table 3}

Frequency and percentage of pretest score of the subjects in the control and experimental group

\begin{tabular}{|c|c|c|c|c|}
\hline \multirow{2}{*}{$\begin{array}{l}\text { Pretest } \\
\text { Score }\end{array}$} & \multicolumn{2}{|c|}{ Control } & \multicolumn{2}{|c|}{ Experimental } \\
\hline & $\mathrm{F}$ & $\%$ & $\mathrm{~F}$ & $\%$ \\
\hline 5 & 0 & 0 & 1 & 2.9 \\
\hline 7 & 0 & 0 & 1 & 2.9 \\
\hline 8 & 0 & 0 & 1 & 2.9 \\
\hline 9 & 2 & 5.9 & 1 & 2.9 \\
\hline 10 & 3 & 8.8 & 1 & 2.9 \\
\hline 11 & 3 & 8.8 & 1 & 2.9 \\
\hline 12 & 3 & 8.8 & 1 & 2.9 \\
\hline 13 & 4 & 11.8 & 3 & 8.6 \\
\hline 14 & 3 & 8.8 & 2 & 5.7 \\
\hline 15 & 5 & 14.7 & 4 & 11.4 \\
\hline 16 & 5 & 14.7 & 3 & 8.6 \\
\hline 17 & 2 & 5.9 & 5 & 14.3 \\
\hline 18 & 2 & 5.9 & 3 & 8.6 \\
\hline 19 & 0 & 0 & 3 & 8.6 \\
\hline 20 & 0 & 0 & 1 & 2.9 \\
\hline 21 & 0 & 0 & 2 & 5.7 \\
\hline 23 & 1 & 2.9 & 0 & 0 \\
\hline 24 & 1 & 2.9 & 1 & 2.9 \\
\hline 33 & 0 & 0 & 1 & 2.9 \\
\hline \multirow{2}{*}{$\begin{array}{r}\text { Total } \\
\text { Composite Mean }\end{array}$} & 34 & 100 & 35 & 100 \\
\hline & \multicolumn{2}{|c|}{14.21} & \multicolumn{2}{|c|}{15.77} \\
\hline
\end{tabular}

Table 3 illustrates the percentage distribution and Frequency of pretest scores of the subjects in two groups with a composite mean of 14.21 and 15.77 for control and experimental, respectively. On the control group, most $\mathrm{f}=5,14.7$ percent) of students got pre-test scores between of 15 and 16 ; some got 13 ( $\mathrm{f}=4,11.8$ percent); 12 $(\mathrm{f}=3=8.8$ percent $) ; 14$ ( $\mathrm{f}=3=8.8$ percent); 17 ( $\mathrm{f}=2,5.9$ percent); 18 ( $\mathrm{f}=2,5.9$ percent); lastly 23 ( $\mathrm{f}=1,2.9$ percent) and $24(\mathrm{f}=1,2.9$ percent) pre- test scores. For experimental group, majority $(\mathrm{f}=17,14.3$ percent) obtained a score of 17 ; followed by 15 ( $\mathrm{f}=4,11.4$ percent); 13 ( $\mathrm{f}=3,8.6$ percent); 16 ( $\mathrm{f}=3,8.6$ percent); 18 ( $\mathrm{f}=3,8.6$ percent); 19 $(\mathrm{f}=3,8.6$ percent); $14(\mathrm{f}=2,5.7$ percent $) ; 21(\mathrm{f}=2,5.7$ percent); and a portion $(\mathrm{f}=1,2.9$ percent) of those who got pretest scores ranging from 5 to $12 ; 20 ; 24$; and 33. Data attests that respondents from both groups have low to average performance during the pretest. 
Flipped classroom instructional strategy in teaching mathematics to grade five learners

\section{Table 4}

Frequency and percentage of post-test score in both group using conventional approach and flipped classroom

\begin{tabular}{ccccc}
\hline Post-Test & \multicolumn{2}{c}{ Control } & \multicolumn{2}{c}{ Experimental } \\
\cline { 2 - 5 } Score & F & $\%$ & F & $\%$ \\
\hline 12 & 1 & 2.9 & 0 & 0 \\
18 & 1 & 2.9 & 0 & 0 \\
19 & 2 & 5.9 & 0 & 0 \\
20 & 5 & 14.7 & 0 & 0 \\
21 & 4 & 11.8 & 0 & 0 \\
22 & 1 & 2.9 & 0 & 0 \\
23 & 3 & 8.8 & 0 & 0 \\
24 & 5 & 14.7 & 0 & 0 \\
25 & 3 & 8.8 & 1 & 2.9 \\
26 & 2 & 5.9 & 0 & 0 \\
27 & 3 & 8.8 & 0 & 0 \\
28 & 1 & 2.9 & 1 & 2.9 \\
29 & 1 & 2.9 & 3 & 8.6 \\
30 & 1 & 2.9 & 7 & 20.0 \\
31 & 1 & 2.9 & 6 & 17.1 \\
32 & 0 & 0 & 7 & 20.0 \\
33 & 0 & 0 & 3 & 8.6 \\
34 & 0 & 0 & 3 & 8.6 \\
35 & 0 & 0 & 1 & 2.9 \\
36 & 0 & 0 & 1 & 2.9 \\
38 & 0 & 0 & 1 & 2.9 \\
40 & & 0 & 1 & 2.9 \\
& & 100 & 35 & 100 \\
& & & & 31.71 \\
\hline
\end{tabular}

Table 4 portrays the percentage distribution and Frequency of score in post-test of the subjects in two groups using the conventional approach and Flipped Classroom. On control group, most $(\mathrm{f}=5 ; 14.7$ percent) of the learner-respondents have a score of 20 and 24. Others have score of 21 ( $\mathrm{f}=4 ; 11.8$ percent); 23 (f-3, 8.8 percent); 25 ( $\mathrm{f}=3,8.8$ percent); $27(\mathrm{f}=3,8.8$ percent $) ; 19$ ( $\mathrm{f}=2,5.9$ percent $) ; 26$ ( $\mathrm{f}=2,5.9$ percent); and few $(\mathrm{f}=1,2.9$ percent) of those who have post- test scores of $12 ; 18 ; 22 ; 28$ to 31 . While on the experimental group, there are plenty $(\mathrm{f}=7,20.0$ percent) of respondents who attained a score of 30 and 32; some with $31(\mathrm{f}=6,17.1$ percent); $29(\mathrm{f}=3$, 8.6 percent); 33 ( $\mathrm{f}=3,8.6$ percent); 34 ( $\mathrm{f}=3,8.6$ percent); and a small number $(\mathrm{f}=1,2.9$ percent) of those with post-test scores of 2; 28; and 35 to 40 . Therefore, the performances of the experimental group and control group have increased. Though, the experimental group has a greater post-test score rating than the control group.

\section{Table 5}

Significant difference between the pretest scores of the control and experimental group-pretest

\begin{tabular}{|c|c|c|c|c|c|c|c|}
\hline Items & $\mathrm{N}$ & Mean & SD & $\begin{array}{c}\text { Computed } \\
t \text {-Value }\end{array}$ & $p$-Value & Decision & Interpretation \\
\hline $\begin{array}{l}\text { Control } \\
\text { Group }\end{array}$ & 34 & 14.21 & 5.12253 & \multirow{2}{*}{0.92814} & \multirow{2}{*}{.180141} & \multirow{2}{*}{ Accept Ho } & \multirow{2}{*}{ NS } \\
\hline $\begin{array}{l}\text { Experimental } \\
\text { Group }\end{array}$ & 35 & 15.77 & 3.46217 & & & & \\
\hline
\end{tabular}

Table 5 shows the significant difference between the pretest scores of the control and experimental group where the control group $(\mathrm{N}=34, \overline{\mathrm{x}}=14.21, \mathrm{SD}=5.12253)$ and experimental group $(\mathrm{N}=35, \overline{\mathrm{x}}=15.77, \mathrm{SD}=$ 3.46217 ) have $\mathrm{t}$ - value of 0.92814 and p-value of .180141which leads to accepting the null hypothesis with the verbal interpretation of not significant. Data indicates that scores in the pretest of both groups do not have a substantial difference. Also, it depicts that respondents' ability on both experimental and control is almost at an equal level. Therefore, an intervention should be used to improve their performance. 
In addition, Salman Khan (2017) supported the reverse trend, saying that video clips could enable the teacher to focus on greater-level learning, such as exercises, seminars with the students, individual activities, and collaborative efforts (Fink, 2017; Gojak, 2017). The reason for school improvements is the main facet of this flipped model. The use of an inverted classroom introduced the teacher to an interactive learning environment that was more student-friendly. The main pedagogical idea did not switch from a floppy classroom to passive listening and observing idea (Nolan \& Washington, 2018). Videos created by a classroom instructor were not even required as videos were easily available on sites like the Khan Academy, YouTube, or Ted (Tucker, 2017).

\section{Table 6}

Significant difference of the post-test scores of the both group-post test

\begin{tabular}{lccccccc}
\hline \multicolumn{1}{c}{ Items } & $\mathrm{N}$ & Mean & $\mathrm{SD}$ & $\begin{array}{c}\text { Computed } \\
t \text {-Value }\end{array}$ & $p$-Value & Decision & Interpretation \\
\hline $\begin{array}{l}\text { Control } \\
\text { Group }\end{array}$ & 34 & 23.21 & 3.87517 & & & & \\
\cline { 1 - 1 } $\begin{array}{l}\text { Experimental } \\
\text { Group }\end{array}$ & 35 & 31.71 & 2.78199 & 0.23918 & .000387 & Reject Ho & $\mathrm{S}$ \\
\hline
\end{tabular}

Table 6 depicts the significant difference between the scores in post-testpost-test of both group where control group $(\mathrm{N}=34, \overline{\mathrm{x}}=23.21, \mathrm{SD}=3.87517)$ and experimental group $(\mathrm{N}=35, \overline{\mathrm{x}}=31.71, \mathrm{SD}=2.78199)$ have $\mathrm{t}-$ value of 0.23918 and p-value of .000387 that rejected the null hypothesis with verbal interpretation of significant. In conclusion, points in the post-test of both groups have substantial differences. Although there is an increase in the group's result in control, the group in experimental has performed even better. Therefore, the implementation of the flipped classroom instructional strategies in teaching Mathematics is deemed effective.

Also, educators who have used the flipped-out classroom recorded positive results in their classrooms, according to the Electronic Education Report [EER] (2017). Students contribute further in their schooling by working together with the instructor and the others to solve problems. Learners started to own their schooling, and instructors started to talk to teachers rather than pupils (EER, 2017). Students received immediate feedback on their teacher's content rather than working at home and not finishing the job due to missing details. A study carried out by Clark (2015) reported the student participants' reacted satisfactorily to flipped instructional paradigm and that their participation and contact improved in contrast to the traditional class experience. Student participants have noticed changes in the instruction's quality and time spent with the inverted teaching paradigm. Some significant changes in academic performance have been shown between the inverted types of school students and those educated in a traditional classroom setting (Clark, 2015).

\section{Conclusions}

Flipped classroom aims specifically at optimizing comprehension and success by changing the traditional classroom layout and spending class time on learner awareness rather than lecture. To do that, instructors upload short online video conferences for students to access at home before the next lecture. In addition, it gives class time to develop and understand the curriculum through joint learning activities, assignments, and discussions. Usually, the research normally accomplished at home is carried out in the classroom, while the school lessons are normally taken at home.

In this respect, the study concludes that respondents from the control and experimental group have low to average performance during the pretest. It concludes that the learners need to view instructional materials like video lectures to increase their performance. Performances of the control group and experimental group have increased. Though, a group in the experimental has a higher post-test score rating than the group in control. This is concluded that the use of video-assisted materials is effective in enhancing the performance of the learners. Pretest points of both groups do not have a substantial difference. Also, it depicts that the ability of respondents on both groups is almost at the same level. Therefore, an intervention should be used to improve their performance due 
Flipped classroom instructional strategy in teaching mathematics to grade five learners

to the learners' level of understanding and in their learning capacity. Scores in the post-test of both groups have substantial differences. Although there is an increase in the group's performance in control, the group in experimental has accomplished even better. It concludes that the application and implementation of flipping the classroom instructional strategies in teaching Math are deemed effective.

Acknowledgments - The author would like to express his gratitude to everyone who helped him write this piece of work. I'd also like to express my gratitude to all of the participants who decided to volunteer their time and enthusiastically share their knowledge and experience on the study's topics. Thanks also to Pipindan Elementary School for providing a conducive atmosphere for the research. Finally, the author wishes to state that the publication of this article does not include any conflicts of interest.

\section{References}

Baker, J. W. (2017). The "classroom flip": Using web course management tools to become the guide by the side. Paper presented at the 11th International Conference on College Teaching and Learning, Jacksonville, FL.

Bergmann, J., \& Sams, A. (2017). How the flipped classroom is radically transforming learning. The Daily Riff. Retrieved May 13, 2017, from http://www.thedailyriff.com/articles/how-the-flipped-classroom-is-radicallytransforming-learning-536.p $\underline{\mathrm{hp}}$

Bergmann, J., \& Sams, A. (2017). The truth about flipped learning. eClassroom News. Retrieved June 4, 2017 , from http://www.eclassroomnews.com/2017/05/31/the-truthabout-flipped-learning/

Bruner, J. S. (2015). The act of discovery. Harvard Educational Review, 31(1), 21-32.

Bruner, J. S. (2015). Toward a theory of instruction. Cambridge, Massachusetts: Harvard University Press.

Bull, G., Ferster, B., \& Kjellstrom, W. (2017, August). Inventing the flipped classroom. Learning \& Leading with Technology, 40(1). Retrieved from http://www.learningandleading-digital.com/learningandleading/

Byrne, T. (2015). The evolution of distance education. Calgary, Alberta: University of Calgary Press.

Clark, K. R. (2015). The effects of the flipped model of instruction on student engagement and performance in the secondary mathematics classroom. Journal of Educators Online, 12(1), 91-115. https://doi.org/10.9743/JEO.2015.1.5

Electronic Education Report. (2017). The flipped classroom offers a new learning path. Electronic Education Report, 18(23), 1-3 Retrieved from http://www.electroniceducationreport.com/content/flipped-classroom-offers-new-learning-path

Fink, Z. (2017, September 30). Big thinkers: Salman Khan on liberating the classroom for creativity. Edutopia: K-12 Education \& Learning Innovations with Proven Strategies that Work. Retrieved May 9, 2017. from http://www.edutopia.org/salman-khan-academyflipped-classroom-video

Gilmartin, M., \& Moore, N. (2018). Teaching for better learning: A blended learning pilot project with first-year geography undergraduates. Journal of Geography in Higher Education, 34(3), 327-344. https://doi.org/10.1080/03098265.2018.501552

Khan, S. H., Hayat, M., Bennamoun, M., Sohel, F. A., \& Togneri, R. (2017). Cost-sensitive learning of deep feature representations from imbalanced data. IEEE transactions on neural networks and learning systems, 29(8), 3573-3587. https://doi.org/10.1109/TNNLS.2017.2732482

Lage, M. L., Platt, G. J., \& Treglia, M. (2017). Inverting the classroom: A gateway to creating an inclusive learning environment. Journal of Economic Education, 31(1), 30-43. https://doi.org/10.1080/00220480009596759

Lotter, C., Marshall, J. C., Sirbu, C., \& Smart, J. (2017). Comparative analysis of two inquiry observational protocols: Striving to better understand the quality of teacher-facilitated inquiry-based instruction. School Science and Mathematics, 111(6), 306-315. https://doi.org/10.1111/j.1949-8594.2017.00091.x

Marlowe, C. A. (2017). The effect of the flipped classroom on student achievement and stress (Unpublished 
master's thesis). Montana State University, Bozeman, MT.

Moffett, J. (2015). Twelve tips for "flipping" the classroom. Medical teacher, 37(4), 331-336. https://doi.org/10.3109/0142159X.2014.943710

Nolan, M. A., \& Washington, S. S. (2018, February). Flipped out: Successful strategies for improving student engagement. Paper presented at Virginia Tech's Conference on Higher Education Pedagogy, Blacksburg, VA.

Piaget, J. (1970). Science of education and psychology of the child. New York: Orion Press.

Rusche, S. N., \& Jason, K. (2017). "You have to absorb yourself in it": Using Inquiry and Reflection to Promote Student Learning and Self-knowledge. Teaching Sociology, 39(4), 338-353. https://doi.org/10.1177/0092055X11418685

Schachter, R. (2017, July/August). Avoiding the pitfalls of virtual schooling: The learning curve for launching programs is well worth the effort. District Administration, 74-79.

Strayer, J. (2007). The effects of the classroom flip on the learning environment: a comparison of learning activity in a traditional classroom and a flip classroom that used an intelligent tutoring system (Doctoral Dissertation). OhioLink ETD Center 1189523914

Tucker, B. (2017, Winter). The flipped classroom: Online instruction at home frees class time for learning. Education Next, 82-83

Zhou, X. W., Wadley, H. N. G., Johnson, R. A., Larson, D. J., Tabat, N., Cerezo, A., ... \& Kelly, T. F. (2001). Atomic-scale structure of sputtered metal multilayers. Acta materialia, 49(19), 4005-4015.

https://doi.org/10.1016/S1359-6454(01)00287-7 